\title{
Catastrophic health expenditure among households with members with special diseases: A case study in Kurdistan
}

\author{
Ghobad Moradi ${ }^{1}$, Hossein Safari ${ }^{2}$, Bakhtiar Piroozi ${ }^{1 *}$, Laila Qanbari ${ }^{3}$, Salahadin Farshadi ${ }^{4}$, \\ Homan Qasri ${ }^{5}$, Fariba Farhadifar ${ }^{1}$
}

\begin{abstract}
Background: One of the main goals of health systems is to protect people against financial risks associated with diseases that can be catastrophic for patients. In 2014, Health Sector Evolution Plan (HSEP) was implemented in Iran; one of the objectives of HSEP was to reduce out-of-pocket payments and provide more financial protection for people. Therefore, the present study aimed at exploring the likelihood of facing catastrophic health expenditures (CHE) among households with members suffering from dialysis, kidney transplant, or multiple sclerosis (MS) after the implementation of HSEP.

Methods: A total number of 385 households were selected using stratified random sampling and were asked to complete the World Health Survey questionnaire through telephone conversations. As outlined by the World Health Organization (WHO), when household out-of-pocket expense for health services is $\geq 40 \%$ of its capacity to pay, then that household is considered to be facing CHE. Furthermore, determinants of CHE were identified using logistic regression.

Results: The percentage of facing catastrophic health care expenditures for households with a MS, dialysis, and kidney transplant patient was $20.6 \%, 18.7 \%$, and $13.8 \%$, respectively. Results of logistic regression analysis revealed that patient's economic status, level of education, supplementary insurance status, type of disease, multiple members with special diseases in the household, rural residence, use of inpatient, dental, and rehabilitation services were effective factors for determining the likelihood of facing CHE.

Conclusion: Despite the implementation of HSEP, the percentage of CHE is still high for households that have members who suffer from special diseases. However, basic health insurance packages should be amended and more cost-sharing exemptions should be granted to provide more financial protection for the vulnerable households.
\end{abstract}

Keywords: Catastrophic Health Expenditures, Health System Reform, Health Expenditures, Dialysis, Kidney Transplant, Multiple Sclerosis (MS)

Copyright@ Iran University of Medical Sciences

Cite this article as: Moradi Gh, Safari H, Piroozi B, Qanbari L, Farshadi S, Qasri H, Farhadifar F. Catastrophic health expenditure among households with members with special diseases: A case study in Kurdistan. Med J Islam Repub Iran. 2017 (2 Aug);31:43. https://doi.org/10.14196/mjiri.31.43

\section{Introduction}

One of the most important dimensions of universal health coverage (UHC), which has received the most attention, is the financial protection of people at the time of paying for health services. In 2005, all members of WHO aimed to develop a health financing system through which people would not face any problem at the time of paying for health services. This goal was later called universal health coverage (UHC) (1). Removing financial barriers that exist in the heart of out-of-pocket payment system helps the poor to access health care services (2). Accord-

Corresponding author: Dr Bakhtiar Piroozi, bpiroozi@gmail.com

1. Social Determinants of Health Research Center, Kurdistan University of Medical Sciences, Sanandaj, Iran.

2. Department of Health Management and Economics, School of Public Health, Tehran University of Medical Sciences, Tehran, Iran.

3. Special Disease Department, Deputy of Treatment, Kurdistan University of Medical Sciences, Sanandaj, Iran.

4. Health Economics Department, Deputy of Treatment, Kurdistan University of Medical Sciences, Sanandaj, Iran.

5. Deputy of Treatment, Kurdistan University of Medical Sciences, Sanandaj, Iran. ing to the WHO report in 2011, the share of private expenditures from total health expenditures has varied from $0.1 \%$ to $84.1 \%$ among countries worldwide, most of the costs in the form of out-of-pocket. The average of this share for countries of East Mediterranean region was $49 \%$ in the same year (3).

Out-of-pocket payment at the time of receiving health services can cause CHE. These costs occur when household health expenditures are equal to or more than $40 \%$ of their residual income after meeting their basic needs (4).

$\uparrow$ What is "already known" in this topic:

In Iran, no study has ever been conducted to measure the exposure of households with members suffering from special diseases with catastrophic health expenditure.

$\rightarrow$ What this article adds:

In Kurdistan province, the percentage of facing catastrophic health care expenditures for households with a multiple sclerosis, dialysis, and kidney transplant patient was $20.6 \%, 18.7 \%$, and $13.8 \%$, respectively. 
As reported by WHO in 2005, annually, 44 million households around the world face CHE (5). Moreover, according to a study conducted in Sanandaj, Iran, $4.8 \%$ of the households had faced CHE in 2015 (6). This percentage was 67.9 for households with cancer patients in Iran in 2014 (7).

Households with disabled members or with members suffering from chronic diseases are more likely to face CHE (8-10). According to a report released by Multiple Sclerosis International Federation, 2.3 million suffer from MS around the world (11). Moreover, 400000 people suffer from MS in the United States, and 10000 new patients are added to this number annually. The annual cost of this disease is over $\$ 9$ billion in the U.S $(11,12)$. As reported by WHO Collaborating Center on Donation and Transplantation, at least 79950 kidney transplants were done in 2014 worldwide (13). In 2013, 17600 kidney transplants were performed in the United States and the kidney transplant waiting lists had 86965 candidates (14). Moreover, the total health care spending on end-stage renal disease was $\$ 32.9$ billion in the US in 2010 (15). In Australia, the number of people who used renal replacement therapy raised from 6643 to 18267 cases between 1991 to 2009 (16). Furthermore, in India, the incidence of end-stage renal disease has been estimated 226 per million population (9). In addition, according to the United Network for Organ Sharing (UNOS), the first-year billed charges for a kidney transplant are more than $\$ 262000$ (17). In England, chronic kidney disease imposes $£ 1.44$ to $£ 1.45$ billion on its health system, which is equal to $13 \%$ of the total national health system expenditures. In addition, dialysis and renal replacement therapy count for $35 \%$ and more than $50 \%$ of these expenditures, respectively (10). The prevalence of MS is 15 to 30 per 100000 in Iran. According to a national study in Iran in 2011, the mean of total annual direct and indirect expenditure per MS patient was estimated to be \$US24475 (18). In 2015, 2700 renal replacement therapies were performed in Iran, and the number of dialysis patients was reported to be 27000 (19). Diseases such as hemophilia, thalassemia, dialysis, renal replacement therapy, and epilepsy are among the special diseases list in Iran (20-22). Special diseases increase the health expenditures, reduce productivity, and cause early retirement or disability among patients $(9,24,25)$. Therefore, it seems that the households with a member suffering from a special disease are more likely to face CHE.

The topic of financial protection of patients against health services expenditures has turned into a highly important issue in Iran. To reach this goal, a series of reforms under the name of "Health Sector Evolution Plan" with 3 approaches of financial protection of patients against health expenditures, improving access to health services, and enhancing the quality of health services have been started since April 30, 2014 (26). As outlined by WHO, increasing the share of health sector from general government budget is the first step to financially protect the population against health expenditures, especially for low and middle income countries (1). This issue has been taken into account in HSEP; in other words, besides the annual budget of the Ministry of Health and Medical Edu- cations (MOHME), $10 \%$ of the revenues from targeted subsidy plan along with $1 \%$ value-added tax have been allocated to the health sector (6). Also, in Iran, universal coverage of health insurance is offered to the uninsured population in the form of HSEP and is free of charge. People with basic health insurance pay $3 \%$ to $6 \%$ of their total hospital bill for public hospitals $(6,26)$. Studies show that implementation of health insurance plan in China, Thailand, and Mexico has reduced the likelihood of facing CHE. However, other studies illustrate that having health insurance does not necessarily protect households against CHE (27-31).

Considering the special conditions of these patients, it seems that households with members suffering from special diseases are more likely to face CHE. Despite the importance of this issue, in Iran no study has ever been conducted to measure the exposure of such households with CHE. Thus, the present study aimed at determining the rate of exposure with $\mathrm{CHE}$ among households with patients suffering from special diseases including dialysis, kidney transplant, or MS in Kurdistan province after the implementation of HSEP. In addition, this study aimed at identifying the effective factors on these expenditures as well.

\section{Methods}

This descriptive-analytical study was conducted using cross-sectional data in Kurdistan province in 2015. Statistical community included all households of the province that had MS, dialysis, or kidney transplant patients among their family members. The number of these households in Kurdistan province in October 2015 was 719, 447, and 554 (this number refers to those patients who had kidney transplants in the previous year), respectively, with a pvalue of $=0.5$ (because no study has been done on the incidence of CHE among special patients in Iran), $\mathrm{d}=$ 0.05 , and $\alpha=0.05$. Sample size was calculated to be 385 using the following formula:

$$
n=\frac{Z^{2}{ }_{1-\frac{\alpha}{2}} \times P(1-P)}{d^{2}}
$$

Sample size was selected randomly and proportionate to the number of households that had members suffering from M.S, dialysis, or kidney transplant. World Health Survey questionnaire was developed by WHO to evaluate the performance of health systems in 2003(31). This questionnaire consists of 2 sections: household and individual. The household section was used to gather data in this study. This section has been translated into Farsi and its validity and reliability were verified by Kavosi et al. (32).

Data were collected through telephone conversations with the household head or the patients themselves if older than 18 years. Their contact numbers were provided by Special Diseases Center of Treatment Deputy for Kurdistan University of Medical Sciences. The recall period for total household expenditure, as well as the household health expenditure was 1 month (the last 30 days). On the other hand, this period was set on 1 month (30 last days) 
and 1 year for frequency of using outpatient and inpatient services, respectively. Households with health expenditures equal to or more than $40 \%$ of their capacity to pay were considered to be facing CHE. Moreover, household capacity to pay is the effective income of the household minus its subsistence expenditure. Meanwhile, household total expenditure was considered as a proxy for household effective income; this income has been considered in many countries as a better measure than the income reported in the household surveys that represents purchasing power. To calculate subsistence expenditure, food poverty line (meaning a part of total household expenditure which is spent on food costs) was used. Xu et al. has reported the methodological details on this subject $(7,34)$.

In addition, patient sex, household head sex, special disease of the household head, household size, patient level of education, marital status, and residence, type of patient basic and supplementary health insurance, type of patient special disease, frequency of using inpatient and outpatient services by the household, use of dentistry and rehabilitation services by the household, average total household expenditure, and average household health expenditure were entered into multiple logistic regression model as independent variables to determine the effective factors on the likelihood of facing CHE. Then, data were analyzed using backward method, with SPSS-20.

\section{Ethical Considerations}

The study was approved by the ethics committee of Kurdistan University of Medical Sciences, Sanandaj, Iran. Participation was voluntary in this study.

\section{Results}

The response rate of the households was $87 \%$. Table 1 displays the demographic characteristics of the studied households. On average, $10.5 \%$ the total monthly household expenditure was spent for health services.

All the studied households had basic health insurance. They had used outpatient and inpatient services at least once for the last month and year, respectively. The percentage of facing CHE for households with MS, dialysis, or kidney transplant patients was $20.6 \%, 18.7 \%$, and $13.8 \%$, respectively (Table 2 ).

\begin{tabular}{|c|c|c|c|}
\hline \multicolumn{2}{|l|}{ Variables } & Mean & Standard Deviation \\
\hline \multicolumn{2}{|c|}{ Monthly household expenditure (Exchange rate: 36000 Iranian Rial to US\$1.00) } & 367.12 US\$ & 132.70 US\$ \\
\hline \multicolumn{2}{|c|}{ Monthly Out-of-pocket health expenditure } & 38.50 US\$ & 27.15 US\$ \\
\hline \multicolumn{2}{|c|}{ Number of times household used inpatient services during the last year } & 1.3 & 0.64 \\
\hline \multicolumn{2}{|c|}{ Number of times household used outpatient services during the last month } & 1.6 & 0.72 \\
\hline \multicolumn{2}{|c|}{ Patient's age } & 50.2 years & 10.12 \\
\hline \multicolumn{2}{|l|}{ Family size } & 4.1 members & 1.15 \\
\hline \multirow[t]{2}{*}{ Variables } & & \multicolumn{2}{|c|}{ Faced with Catastrophic Health Expenditures } \\
\hline & & Yes $(\%)$ & No $(\%)$ \\
\hline \multirow[t]{2}{*}{ Sex of the patient } & Male & $32(21.2)$ & $119(78.8)$ \\
\hline & Female & $29(15.8)$ & $155(84.2)$ \\
\hline \multirow[t]{2}{*}{ Sex of the household head } & Male & $53(18.2)$ & $238(81.8)$ \\
\hline & Female & $8(18.2)$ & $36(81.8)$ \\
\hline \multirow[t]{2}{*}{ Is household head the patient? } & Yes & $40(21.3)$ & $148(78.7$ \\
\hline & No & $21(14.3)$ & $126(85.7)$ \\
\hline \multirow[t]{3}{*}{ Household size } & $1-2$ & $7(14.3)$ & $42(85.7)$ \\
\hline & $3-4$ & $30(20)$ & $120(80)$ \\
\hline & $>4$ & $24(17.6)$ & $112(82.4)$ \\
\hline \multirow[t]{5}{*}{ Household's economic status * } & First quintile (poorest) & $25(25)$ & $81(75)$ \\
\hline & Second quintile & $17(20.7)$ & $65(79.3)$ \\
\hline & Third quintile & $14(18.9)$ & $60(81.1)$ \\
\hline & Fourth quintile & $4(8)$ & $46(92)$ \\
\hline & Fifth quintile (richest) & $1(4.3)$ & $22(93.7)$ \\
\hline \multirow[t]{4}{*}{ level of education } & Illiterate & $18(23.1)$ & $60(76.9)$ \\
\hline & Primary and Middle school & $23(21.1)$ & $86(78.9)$ \\
\hline & High school and Diploma & $9(10)$ & $81(90)$ \\
\hline & University & $11(19)$ & $47(81)$ \\
\hline \multirow[t]{2}{*}{ Residence } & Urban & $47(20)$ & $188(80)$ \\
\hline & Rural & $14(14)$ & $86(86)$ \\
\hline \multirow[t]{4}{*}{ Marital status } & Single & $3(20)$ & $12(80)$ \\
\hline & Married & $45(18.1)$ & $203(81.9)$ \\
\hline & Divorced & $7(16.7)$ & $35(83.3)$ \\
\hline & Widowed & $6(20)$ & $24(80)$ \\
\hline \multirow[t]{5}{*}{ Type of basic insurance } & Medical services & $18(13.1)$ & $119(86.9)$ \\
\hline & Social security & $26(23.4)$ & $85(76.6)$ \\
\hline & Armed forces & $9(17)$ & $44(83)$ \\
\hline & Relief Committee & $4(23.5)$ & $13(76.5)$ \\
\hline & Others & $4(23.5)$ & $13(76.5)$ \\
\hline
\end{tabular}

*Based on monthly total expenditure by the household 


\begin{tabular}{|c|c|c|c|}
\hline Supplementary insurance status & Yes & $3(13.6)$ & $19(86.4)$ \\
\hline \multirow{4}{*}{ Type of disease } & No & $58(18.5)$ & $255(81.5)$ \\
\hline & Dialysis & $12(13.8)$ & $75(86.2)$ \\
\hline & Multiple sclerosis & $29(20.6)$ & $112(79.4)$ \\
\hline & Kidney Transplantation & $20(18.7)$ & $87(81.3)$ \\
\hline \multirow[t]{2}{*}{ Multiple members with special disease in the household } & Yes & $5(55.6)$ & $4(44.4)$ \\
\hline & No & $56(17.2)$ & $270(82.8)$ \\
\hline \multirow[t]{2}{*}{ Use of dental services } & Yes & $23(28.8)$ & $57(71.2)$ \\
\hline & No & $38(14.9)$ & $217(85.1)$ \\
\hline \multirow[t]{2}{*}{ Use of rehabilitation services } & Yes & $13(27.7)$ & $34(72.3)$ \\
\hline & No & $48(16.7)$ & $240(83.3)$ \\
\hline
\end{tabular}

Table 3. Determinants of catastrophic health expenditures, 2015

\begin{tabular}{|c|c|c|c|c|}
\hline \multirow[b]{2}{*}{ Variables } & \multirow[b]{2}{*}{ OR } & \multicolumn{2}{|c|}{ Confidence Interval $(95 \%)$} & \multirow[b]{2}{*}{$\mathrm{p}$} \\
\hline & & Lowest & Highest & \\
\hline \multicolumn{5}{|l|}{ Level of education } \\
\hline Illiterate (Reference Category) & 1 & - & - & \\
\hline Primary and Middle school & 0.84 & 0.51 & 2.21 & 0.212 \\
\hline High school, Diploma and University & 0.46 & 1.24 & 2.61 & 0.012 \\
\hline \multicolumn{5}{|l|}{ Household's economic status * } \\
\hline Fifth quintile (Reference Category) & 1 & - & - & \\
\hline Fourth quintile & 2.70 & 1.31 & 6.02 & 0.025 \\
\hline Third quintile & 4.38 & 3.02 & 9.92 & 0.029 \\
\hline Second quintile & 5.40 & 3.81 & 12.91 & 0.036 \\
\hline First quintile (poorest) & 7.21 & 4.41 & 15.45 & 0.041 \\
\hline \multicolumn{5}{|l|}{ Supplementary insurance status } \\
\hline Yes (Reference Category) & 1 & - & - & \\
\hline No & 1.44 & 1.04 & 4.88 & 0.023 \\
\hline \multicolumn{5}{|l|}{ Type of disease } \\
\hline Dialysis (Reference Category) & 1 & - & - & \\
\hline Multiple sclerosis & 2.10 & 1.38 & 4.22 & 0.020 \\
\hline Kidney Transplantation & 1.40 & 0.78 & 3.44 & 0.154 \\
\hline \multicolumn{5}{|l|}{ Family member with a special disease } \\
\hline 1 member (Reference Category) & 1 & - & - & \\
\hline More than 1 member & 5.50 & 1.33 & 19.11 & 0.048 \\
\hline \multicolumn{5}{|l|}{ Residence } \\
\hline Urban (Reference Category) & 1 & - & - & \\
\hline Rural & 1.90 & 0.83 & 4.61 & 0.118 \\
\hline Frequent use of inpatient services & 1.70 & 1.11 & 2.39 & 0.011 \\
\hline \multicolumn{5}{|l|}{ Use of dental care } \\
\hline No (Reference Category) & 1 & - & - & \\
\hline Yes & 2.34 & 1.51 & 4.76 & 0.036 \\
\hline \multicolumn{5}{|l|}{ Use of rehabilitation services } \\
\hline No (Reference Category) & 1 & - & - & \\
\hline Yes & 2.33 & 1.46 & 5.77 & 0.042 \\
\hline Constant & 0.02 & 0.007 & 0.016 & 0.031 \\
\hline$-2 \mathrm{LL}=461.336 \mathrm{a} ;$ Cox \& Snell R squa & are $=0.2$ & & & \\
\hline
\end{tabular}

*Based on monthly total expenditure by the household

\section{Effective Factors on Catastrophic Expenditures}

Table 3 demonstrates the results of logistic regression. The most important factors were as follow: patient's education; household income; patient supplementary insurance status; type of special disease; a family member with a special disease; patient residence; frequency of using inpatient services; use of dental care; and use of rehabilitation services.

Patient' Education: Illiterate patients are more likely to face CHE.

Household's Economic Status: The odds of facing CHE decreased as the household economic level increased. For example, the households in the first quintile were 7 fold more likely to face CHE compared to the households in the fifth quintile.

Patient Supplementary Insurance Status: Households in which the patient did not have supplementary insurance were $44 \%$ more likely to pay for $\mathrm{CHE}$ compared to households with supplementary insurance.
Type of Special Disease: Households having MS or renal replacement patients were respectively 2.1 and 1.4 times more likely to face CHE compared to households with a dialysis patient. This difference was not significant for kidney transplant patients.

Family Member with a Special Disease: Households having more than 1 member with special disease were 5.5 times more likely to face CHE compared to those having only 1 member with special disease.

Patient Residence: Living in rural areas increased the chance of facing CHE by $90 \%$, but this was not statistically significant.

Frequency of Using Inpatient Services: The possibility of facing $\mathrm{CHE}$ increased by $70 \%$ per any increase in the use of inpatient services by households.

Use of Dental Care: The household use of dental care for the last 30 days increased the likelihood of facing CHE up to 2.3 times.

Use of Rehabilitation Services: The Household use of 
rehabilitation services for the last 30 days increased the possibility of facing CHE up to 2.3 times.

The results of Hosmer-Lemeshow test $(p=0.276)$ verified the accuracy of the model.

\section{Discussion}

Based on the definition of CHE by WHO, the results of our study revealed that $18.2 \%$ of the households with at least 1 dialysis, renal replacement, and MS patient had faced CHE. These findings indicated that merely having basic health insurance does not necessarily protect such households against CHE. Long period of illness and high costs of treatment and disability increase the possibility of facing $\mathrm{CHE}$ among these households. Moreover, intersectoral collaboration is necessary to provide more financial protection for these households and improve economic status, reinforce basic health insurance package, and exempt them from paying some of the health expenditures. According to the results of an Indian study in 2013, 82\% of the people, who had renal replacement, experienced financial crisis during their treatment period. This crisis was reported to be highly severe for $54 \%$ of the studied group (9). Furthermore, Delavari et al. found that $67.9 \%$ of the households with a cancer patient had faced CHE in 2014 in Iran (7). Our study results revealed that household economic status was one of the effective factors on probability of facing CHE. Households with lower economic levels were more likely to have CHE. However, other national and foreign studies have shown a reverse relationship between household economic status and possibility of having $\mathrm{CHE}(6,8,33)$.

Results of our study indicated that households with an MS, dialysis, or renal replacement patient had, respectively, paid 44.1, 35 and 36.4 US\$, on average, for health services per month. Based on a national study in 2011, the average annual direct and indirect expenditures for a multiple sclerosis patient were estimated to be US\$ 24475 (18). In India, the average direct and indirect expenditures for renal replacement in public hospitals were US\$7781 and US\$3862, respectively. Additionally, $62 \%$ of the studied group lived below poverty line and $46 \%$ had sold their properties to afford a part of their renal replacement costs (9).

Moreover, our study indicated that households, which had multiple family members with special diseases, were almost 5.5 times more likely to face CHE compared to those with only 1 patient. The former households had paid more medical expenditures. Based on a national study, households that had a disabled member at home were more likely to pay for CHE (8). Somkotra et al. concluded that presence of a chronically ill or disabled patient in the household is the main factor for facing CHE (35).

According to the results of the present study, households in which patients did not have supplementary insurance were $44 \%$ more likely to pay for CHE compared to those with supplementary insurance. As Kavosi et al. showed in their study, households whose heads were not covered by supplementary insurance had 75\% more chance of facing CHE compared to those who had supplementary insurance (8). In Iran, nationally produced medicines for patients with special diseases are provided free of charge; the costs for these diseases are financed by MOHME. However, deductible and the price difference between national and foreign medicines are paid by patients. Supplementary insurance covers these deductibles and price differences in Iran. These insurances are private and voluntarily, and most families can't afford them. In Thailand, costs of dialysis treatments and chemotherapies, which were not covered by insurance companies, have had CHE for households after the implementation of UHC (36).

In addition, our findings revealed that households with an MS or renal replacement patient were more likely to have $\mathrm{CHE}$ than households with dialysis patients. Patients are not asked to pay for dialysis treatment in Iranian hospitals. Moreover, the official price of kidney in Iran is 15 million Iranian Tomans (equivalent to US\$5000); MOHME and insurance companies do not participate in paying this cost, and it is paid either by the patient or charity organizations (37). Furthermore, patients with special diseases do not pay anything if hospitalized in Iranian public hospitals. The price of foreign medicines for MS patients is very high in Iran and patients without supplementary insurance have to pay high costs for these medicines.

According to our study, illiteracy increases the possibility of facing CHE. This is due to the fact that illiterate patients have weaker occupational and economic conditions, so they spend more of their financial capacity to pay for health expenditures. As pointed out by Fazaeli et al., education level is one of the main determinants for facing CHE (38). Furthermore, an Indian study showed that educational dropout and unemployment were the main threats for people who had renal replacement (9).

Additionally, rural residence increases the chance of facing CHE; this finding has also been confirmed by other studies $(4,8,38)$. This disparity is due to the lower income of rural residents, as well as their high indirect costs to access health services.

Households that had used dental and rehabilitation services were 2.3 times more likely to face $\mathrm{CHE}$ compared to those that had not used these services. This finding was also supported by Kavosi et al. (8). Most of the dental and rehabilitation services are not covered by basic health insurance companies and patients should afford these costs. However, MS patients can use free physiotherapy services up to 80 sessions. Overall, supplementary insurances reimburse dental and rehabilitation services up to a certain level. It is necessary to cover these services to provide more financial protection for the families with patients suffering from special diseases.

Moreover, households that had used inpatient services more frequently were more likely to experience CHE. Despite the implementation of HSEP and the dramatic decrease in the share of hospitalized patients to $3 \%$ and $6 \%$ of hospital bills (6), it is possible for these $3 \%$ to $6 \%$ deductibles to turn into $\mathrm{CHE}$ due to the households' increased use of inpatient services. Because these patients usually lose their jobs either permanently or temporally, the "capacity to pay" of these households is very small. 
Exempting these households from paying for inpatient services seems vital to reduce their $\mathrm{CHE}$ and protect them more. National and foreign studies have confirmed the relationship between using health services and experiencing $\mathrm{CHE}(4,8)$.

\section{Conclusion}

Despite the fact that a year has been passed from the implementation of HSEP, the percentage of CHE is still high among households with special patients. Undoubtedly, one of the reasons for this lies in the specific conditions of these patients such as the long period of their illness and disability. However, more researches should be conducted to uncover the effects of HSEP on CHE in the long- term.

Based on our results, it is important to increase the depth and coverage of basic health insurances and consider more cost-sharing exemption to protect these households more. Additionally, intersectoral policies should be improved to enhance their economic status.

\section{Limitations}

This study was conducted in Kurdistan province, located at the West of Iran, thus, the findings of this study might not be a representative picture of CHE status among households with members suffering from special diseases in Iran after implementation of HSEP. Furthermore, there was a possibility of over or under-reporting of the expenditures along with the recall bias of the participants. In addition, in this study, the items of money saving and borrowing were not considered for estimating the CHE.

\section{Acknowledgments}

We would like to thank the Social Determinants of Health Research Center as well as Special Disease Center of Treatment Deputy of Kurdistan University of Medical Sciences for their sincere cooperation. This article has been based on a research project financially supported and approved by the research Deputy of Kurdistan University of Medical Sciences (letter No. 94/104).

\section{Conflict of Interests}

The authors declare that they have no competing interests.

\section{References}

1. World Health Organization. The world health report: health systems financing: the path to universal coverage: executive summary. 2010.

2. Van Doorslaer E, O'Donnell O, Rannan-Eliya RP, Somanathan A, Adhikari SR, Garg CC, et al. Catastrophic payments for health care in Asia. Health Econ. 2007;16(11):1159-84.

3. World Health Organization. World health statistics 2010: World Health Organization; 2010.

4. Li Y, Wu Q, Xu L, Legge D, Hao Y, Gao L, et al. Factors affecting catastrophic health expenditure and impoverishment from medical expenses in China: policy implications of universal health insurance. Bull World Health Organ. 2012;90(9):664-671.

5. World Health Organization. Designing health financing systems to reduce catastrophic health expenditure. 2005

6. Piroozi B, Moradi G, Nouri B, Mohammadi A. Catastrophic Health Expenditures after the Implementation of Health Sector Evolution Plan in Iran: A Case Study in the West of Iran. Int J Health Policy Manag.
2016;5(7):417-423

7. Delavari H, Keshtkaran A, Setoudehzadeh F. Catastrophic Health Expenditures and Coping Strategies in Households with Cancer Patients in Shiraz Namazi Hospital. Midd East J Cancer. 2014;5(1):1322.

8. Kavosi Z, Keshtkaran A, Hayati R, Ravangard R, Khammarnia M. Household financial contribution to the health System in Shiraz, Iran in 2012. Inter J Health Policy Manag. 2014;3(5):243-249.

9. Ramachandran R, Jha V. Kidney transplantation is associated with catastrophic out of pocket expenditure in India.PLoS One.2013;8(7):16.

10. Kerr M, Bray B, Medcalf J, O'Donoghue DJ, Matthews B. Estimating the financial cost of chronic kidney disease to the NHS in England. Nephrol Dial Transplant. 2012;27(3):73-80.

11. Multiple Sclerosis International Federation. Atlas of MS 2013. Available from: https://www.msif.org/wp-content/uploads/2014/09/ Atlas-of-MS.pdf. Accessed 23 September 2016.

12. Hartung DM, Bourdette DN, Ahmed SM, Whitham RH. The cost of multiple sclerosis drugs in the US and the pharmaceutical industry too big to fail? Neurology. 2015;84(21):2185-92.

13. Organ donation and transplantation activities, 2014. Available from: http://www.transplant-observatory.org. Accessed 12 September 2016.

14. United States Renla Data System, 2013. Available from: https://www.usrds.org/2015/view/v2_07.aspx. Accessed 12 September 2016.

15. National Institute of Diabetes and Digestive and Kidney Diseases Costs of ESRD. In U.S. Renal Data System, USRDS 2012 Annual Data Report: Atlas of End-Stage Renal Disease in the United States. Bethesda, MD: National Institutes of Health, National Institute of Diabetes and Digestive and Kidney Diseases. 2012.

16. Australian Institute of Health and Wealfare. Authorative information and statistics to promote better health and wellbeing. Dialysis and kidney transplantation in Australia. 2012.

17. UNOS Transplant Living, 2016. Available from: https:// transplantliving.org/index.php. Accessed 12 September 2016.

18. Imani A, Golestani M, Omrani A, Alikhani M, Delpasand M, Vafaee R, et al. Analysis of Therapeutic Expenditure in Patients with Multiple Sclerosis in Iran. sjimu. 2014; 21 (7):169-177.

19. Najafi zade K. 2700 kidney transplants performed annually in Iran, 2014. Available from: http://www.salamatonline.ir. Accessed 8 September 2016.

20. Aghighi M, Heidary Rouchi A, Zamyadi M, Mahdavi-Mazdeh M, Rajolani H, Ahrabi S, et al. Dialysis in Iran. Iran J Kidney Dis. 2008;2(1):11-15.

21. Aghighi M, Mahdavi-Mazdeh M, Zamyadi M, Heidary Rouchi A, Rajolani H, Nourozi S. Changing epidemiology of end-stage renal disease in last 10 years in Iran. Iran J Kidney Dis. 2009;3(4):192-196.

22. Mahdavi-Mazdeh M, Zamyadi M, Nafar M. Assessment of management and treatment responses in haemodialysis patients from Tehran province, Iran. Nephrology Dialysis Transplantation. 2008;23(1):288-293.

24. Iezzoni LI, Ngo L, Kinkel RP. Social security disability application experiences of people with multiple sclerosis in the United States. Int J MS Care. 2007;9(4):131-138.

25. Torabipour A, Asl ZA, Majdinasab N, Ghasemzadeh R, Tabesh H, Arab M. A Study on the Direct and Indirect Costs of Multiple Sclerosis Based on Expanded Disability Status Scale Score in Khuzestan, Iran. Int J Prev Med. 2014;5(9):1131-38

26.Moradi G, Piroozi B, Safari H, Esmailnasab N, Mohammadibolbanabad A, Yari A. Assessment of the Efficiency of Hospitals Before and After the Implementation of Health Sector Evolution Plan in Iran Based on Pabon Lasso Model. Iran J Public Health. 2017;46(3):389-395.

27. Marten R, McIntyre D, Travassos C, Shishkin S, Longde W, Reddy $\mathrm{S}$, et al. An assessment of progress towards universal health coverage in Brazil, Russia, India, China, and South Africa (BRICS). Lancet. 2014;384(9960):2164-71.

28. Hanvoravongchai P. Health Financing Reform in Thailand: Toward Universal Coverage under Fiscal Constraints. The World Bank, Washington DC;2013.

29. Bonilla-Chacín ME, Aguilera N. The Mexican Social Protection System in Health. The World Bank, Washington DC;2013.

30. Knaul F, Gonzalez-Pier E, Gomez-Dantes O, García-Junco D, Arreola-Ornelas H, Barraza-Llorens M, et al. The quest for universal health coverage: achieving social protection for all in Mexico. Salud 
Publica Mex. 2013;55(2):207-235

31. Liang L, Langenbrunner JC. The Long March to Universal Coverage: Lessons from China. The World Bank, Washington DC;2013.

32. Casado V, Martínez-Yélamos S, Martínez-Yélamos A, Carmona O, Alonso L, Romero L, et al. Direct and indirect costs of Multiple Sclerosis in Baix Llobregat (Catalonia, Spain), according to disability. BMC Health Serv Res. 2006;6(1):143-151

33. Kavosi Z, Rashidian A, Pourreza A, Majdzadeh R, Pourmalek F, Hosseinpour AR, et al. Inequality in household catastrophic health care expenditure in a low-income society of Iran. Health Policy Plan. 2012;27(7):613-623.

34. Xu K, Evans DB, Carrin G, Aguilar-Rivera AM, Musgrove P, Evans T. Protecting households from catastrophic health spending. Health Aff. 2007;26(4):972-983.

35. Somkotra T, Lagrada LP. Which households are at risk of catastrophic health spending: experience in Thailand after universal coverage. Health Aff. 2009;28(3):467-478.

36. Limwattananon S, Tangcharoensathien V, Prakongsai P. Catastrophic and poverty impacts of health payments: results from national household surveys in Thailand. Bull World Health Organ. 2007;85(8):600-606.

37. Ramazanpour. A. The official price of kidney was 15 million tomans, 2015. http://www.tasnimnews.com/fa/news/1394/01/26/712165. Accessed 20 Septamber 2016.

38. Abolhallaje M, Hasani S, Bastani P, Ramezanian M, Kazemian M. Determinants of catastrophic health expenditure in iran. Iran J Public Health. 2013;42(Supple1):155-160.

39. Yardim MS, Cilingiroglu N, Yardim N. Catastrophic health expenditure and impoverishment in Turkey. Health Policy. 2010;94(1):26-33 